\title{
Microwave-Assisted Synthesis of Graphene Supported Hexagonal Magnetite for Applications in Catalysis
}

\author{
Hany A. Elazab, M. A. Radwan, M. A. Sadek
}

\begin{abstract}
Herein, we report a rapid one-step synthetic method using microwave irradiation for growing magnetite nanocrystals on reduced graphene oxide sheets. This developed strategy allows decorating graphene sheets with magnetite nanocrystals of welldefined morphology as cubes using microwave-driven reduction of iron chloride using hydrazine hydrate as a reducing agent. The size and shape control was achieved via fine-tuning of the reaction conditions. The obtained results demonstrate the applicability of this microwave synthetic approach to control the morphology of the magnetite nanocrystals anchored on graphene sheets. Moreover, graphene sheets will enhance the nucleation and growth of magnetite nanoplates anchored on graphene. This approach can be used as a synthetic tool to synthesize a wide variety of metal and metal oxide architectures on graphene. This approach also provides plenty of advantages like catalyst recyclability, mild reaction conditions, easy separation, reproducibility, and minimization of agglomeration effect that cause the decrease in the catalyst catalytic activity.
\end{abstract}

Index Terms: Graphene, Cross-Coupling, Hexagonal Magnetite $\left(\mathrm{Fe}_{3} \mathrm{O}_{4}\right)$, Microwave synthesis, Catalyst recycling

\section{I.INTRODUCTION}

The unique properties of metal nanoparticles leads to endless efforts to investigate the possibility to design modern catalytic systems[ 1-4]. There are many crucial issues in the catalysis field including not only environmental concerns, economic impact, high catalytic activity, catalyst recyclability, reproducibility, but also including the scale-up technical issues [5-14]. Several methodologies have been adopted to avoid those issues through implementing bottomup approaches, fine tuning the reaction conditions in order to control the particle size and investigating potential carbon-based materials including active carbon, graphene and carbon nanotubes [15-38]. Recently, several protocols have been adopted to prepare magnetic nanoparticles including several synthetic routes [15, 16, 20-34]. The adopted methodologies used special support of high surface area including graphene [7-14].

Revised Manuscript Received on October 30, 2019.

* Correspondence Author

Hany A. Elazab ${ }^{*}$, Department of Chemical Engineering,

The British University in Egypt, El-Shorouk City, Cairo, Egypt E-mail: elazabha@vcu.edu

M. A. Radwan, Department of Chemical Engineering,

The British University in Egypt, El-Shorouk City, Cairo, Egypt.

M. A. Sadek' Department of Chemical Engineering,

The British University in Egypt, El-Shorouk City, Cairo, Egypt.

(C) The Authors. Published by Blue Eyes Intelligence Engineering and Sciences Publication (BEIESP). This is an open access article under the CC-BY-NC-ND license http://creativecommons.org/licenses/by-nc-nd/4.0/

The graphene unique structure enable the efficient dispersion of the metallic nanoparticles to its surface. [3136] The unique magnetic properties of magnetite nanoparticles allows those kinds of magnetic based catalysts to be ideal candidates for being used in biomedical, chemical, physical, biological, environmental, and other engineering fields of industrially strategic reactions [24, 32, 35].

In this research, we could design a unique magnetic catalyst of controlled hexagonal shape using microwave-assisted synthesis approach to prepare magnetic based nanocomposite with a superior catalytic performance.

\section{II.EXPERIMENTAL SECTION}

Chemicals were purchased and used without any purification.

\subsection{Catalyst Preparation}

2.1.1 Synthesis of Graphene Oxide (GO).

Modified Hummers method was used in preparation of graphene oxide (GO) [30-33].

2.1.2 Microwave-assisted synthesis of Graphene supported $\mathrm{Pd} / \mathrm{Fe}_{3} \mathrm{O}_{4}$.

In the typical synthetic procedure, $388 \mu \mathrm{L}$ of palladium nitrate was added to $100 \mathrm{~mL}$ solution containing $100 \mathrm{mg}$ ferric chloride dissolved in DI water while continuous stirring is applied until obtaining a clear solution.

Hence, $600 \mu \mathrm{L}$ of hydrazine hydrate were added as a reducing agent. Then, the entire mixture was placed in microwave for heating for 25 minutes using $30 \mathrm{~s}$ intervals procedure. The prepared $\mathrm{Pd} / \mathrm{Fe} 3 \mathrm{O} 4$ was then dried overnight.

\subsection{Catalyst Characterization.}

Particle size was confirmed via TEM images. The synthetic protocol was strictly implemented [35]

\section{RESULTS SECTION}

\subsection{Suzuki cross - coupling screening procedure}

Table 1 gives an indication of the catalyst performance using graphene supported palladium in case of using controlled hexagonal shape of magnetite. The results reveal that this can be an ideal catalyst for the investigated crosscoupling reaction with conversion of $100 \%$. 
Table 1 Effect of using 1 mol\% Graphene supported $\mathrm{Pd} / \mathrm{Fe}_{3} \mathrm{O}_{4}$ on the conversion percentage.

\begin{tabular}{|ccc|}
\hline $\begin{array}{c}\text { Temperature } \\
\left({ }^{\mathbf{0}} \mathbf{C}\right)\end{array}$ & $\begin{array}{c}\text { Time } \\
\text { (min.) }\end{array}$ & Conversion \% \\
\hline $25^{\mathbf{0}} \mathbf{C}$ & 180 & 100 \\
\hline $\mathbf{6 0}^{\mathbf{0}} \mathbf{C}$ & 10 & 85 \\
\hline $\mathbf{8 0}^{\mathbf{0}} \mathbf{C}$ & 10 & 100 \\
\hline $\mathbf{1 0 0}^{\mathbf{0}} \mathbf{C}$ & 10 & Conversion $<80$ \\
\hline
\end{tabular}

TEM images indicate the well dispersion of nanoparticles on the support surface. It is remarkable to indicate the enhancement effect caused by using graphene as an ideal support as shown in Figure 1.
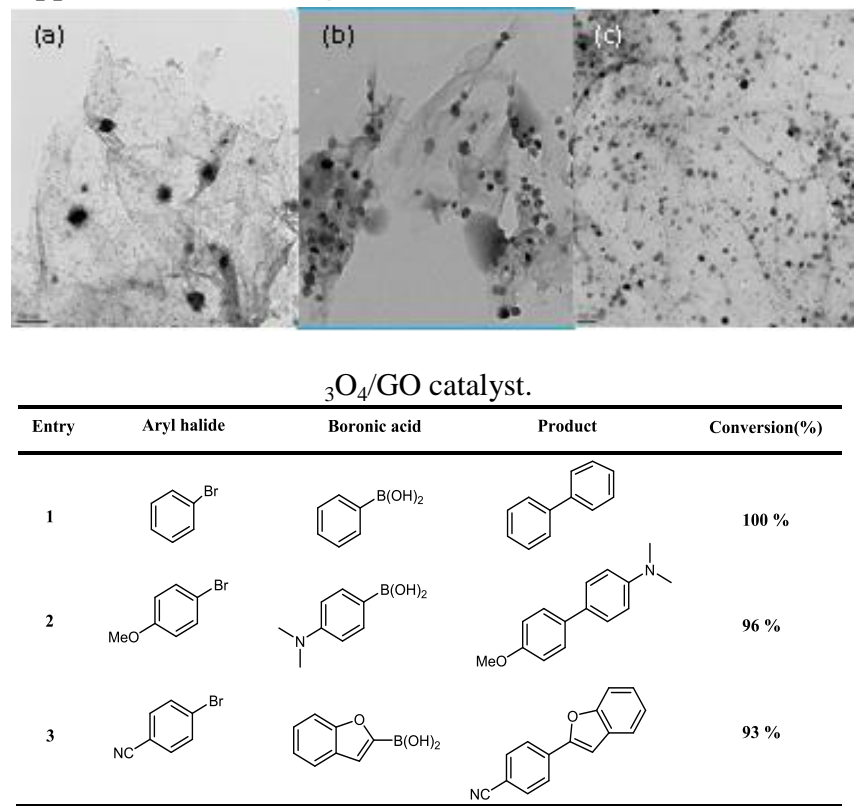

Figure 2 displays the XRD pattern with a sharp diffraction peak at $2 \theta=40^{\circ}$ in case of palladium, while it also confirm the presence of magnetite.

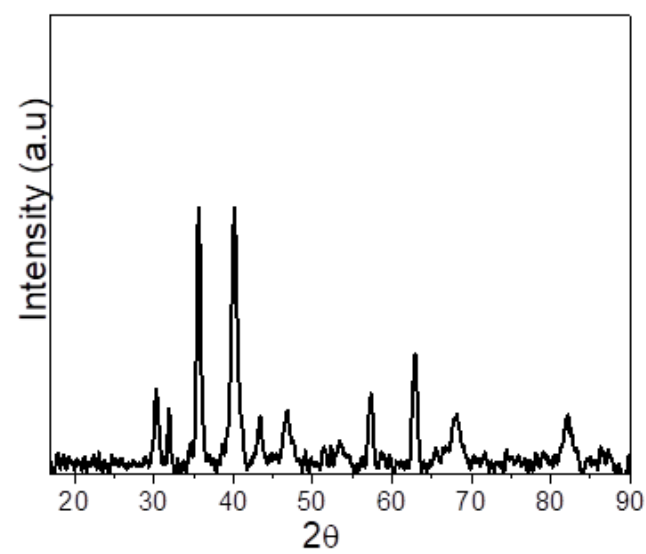

Figure 2. XRD of $\mathrm{Pd} / \mathrm{Hexagonal} \mathrm{Fe}_{3} \mathrm{O}_{4}$ supported on Graphene.

Hexagonal magnetite enhances the catalyst catalytic activity and it is easy to be separated from the reaction mixture using a strong magnet.

Table 3 confirms that the catalyst was recycled seven times with high conversion.
Table 3. Recycling of $1 \mathrm{~mol} \%$ Graphene supported $\mathrm{Pd} / \mathrm{Fe}_{3} \mathrm{O}_{4}$ catalyst

\begin{tabular}{cc} 
Run & $\begin{array}{c}\text { Conversion (\%) } \\
(\mathbf{1} \text { mol \%) }\end{array}$ \\
\hline 1 & 100 \\
\hline 2 & 100 \\
\hline 3 & 100 \\
\hline 4 & 98 \\
\hline 5 & 95 \\
\hline 6 & 93 \\
\hline 7 & 90 \\
\hline 8 & 87 \\
\hline 9 & 81 \\
\hline
\end{tabular}

\section{IV.CONCLUSIONS}

A reproducible and efficient method using microwaveassisted synthesis technique was developed in order to prepare a highly efficient catalyst. $\mathrm{Pd}-\mathrm{Fe}_{3} \mathrm{O}_{4} / \mathrm{G}$ catalyst wase recycled seven times due to the nice dispersion of palladium nanoparticles and hexagonal magnetite nanoparticles on the surface of graphene support.

\section{ACKNOWLEDGEMENTS}

We are grateful to the support of British University in Egypt (BUE), VCU, EAF, EPRI, and STCE.

\section{REFERENCES}

1. Baruwati, B., Magnetically recoverable supported ruthenium catalyst for hydrogenation. Tetrahedron Letters, 50(11): p. 1215-1218, 2009.

2. Tarek M. Aboul-Fotouh, Sherif K. Ibrahim, M. A. Sadek, Hany A. Elazab, International Journal of Innovative Technology and Exploring Engineering (IJITEE), 2019.

3. Yan, J.M., Magnetically recyclable Fe-Ni alloy catalyzed dehydrogenation of ammonia. Journal of Power Sources, 194(1): p. 478481, 2009.

4. Hany A. Elazab, Tamer T. El-Idreesy, Bulletin of Chemical Reaction Engineering and Catalysis, 2019.

5. B. Ashraf, M. A. Radwan, M. A. Sadek, H. A. Elazab International Journal of Engineering and Technology(UAE), 2018, 7, 1295-1298.

6. Hany A. Elazab, Ali R. Siamaki, B. Frank Gupton, M. Samy El-Shall, Bulletin of Chemical Reaction Engineering and Catalysis, 2019.

7. N. S. Samir, M. A. Radwan, M. A. Sadek, H. A. Elazab International Journal of Engineering and Technology(UAE), 2018, 7, 1290-1294.

8. H. A. Elazab, M. A. Sadek, T. T. El-Idreesy Adsorption Science \& Technology, 2018, 36, 1352-1365.

9. F. Zakaria, M. A. Radwan, M. A. Sadek, H. A. Elazab, International Journal of Engineering and Technology, 2018, 7, 4, 1983-1988.

10.R. Nasser, M. A. Radwan, M. A. Sadek, H. A. Elazab, International Journal of Engineering and Technology, 2018, 7, 4, 1989-1994.

11.M. Ghobashy, M. Gadallah, T. T. El-Idreesy, M. A. Sadek, H. A Elazab, International Journal of Engineering and Technology, 2018, 7, 4, 1995-1999.

12.H. A. Elazab, M. A. Sadek, T. T. El-Idreesy Adsorption Science \& Technology, 2018, 36, 5-6, 1352-1365.

13.H. A. Elazab, Biointerface Research in Applied Chemistry, 2018, 8, 3314-3318.

14.H. A. Elazab, Biointerface Research in Applied Chemistry, 2018, 8, 3278-3281.

15.H. A. Elazab, M. A. Radwan, T. T. El-Idreesy International Journal of Nanoscience, 2018, 17, 3, 1850032.

16.Tarek M. Aboul-Fotouh, Eslam Alaa, M. A. Sadek, Hany A. Elazab, International Journal of Innovative Technology and Exploring Engineering (IJITEE), 2019.

17.Hany A. Elazab, The Canadian Journal of Chemical Engineering, 2019.

18.Hany A. Elazab, Mamdouh Gadall, M. A. Sadek, Tamer T. El-Idreesy, , Biointerface Research in Applied Chemistry, 2019. 
19.M. A. Radwan, Mohamed Adel Rashad, M. A. Sadek, Hany A. Elazab, Journal of Chemical Technology and Metallurgy, 2019.

20.W. Mohsen, M. A. Sadek, H. A. Elazab International Journal of Applied Engineering Research, 12, 14927-14930.

21.R. A. Mankarious, M. A. Radwan, M. Shazly, H. A. Elazab Journal of Engineering and Applied Sciences, 12, 2697-2701.

22.Marwa M. Naeem, M. A. Radwan, M. A. Sadek, H. A. Elazab Journal of Engineering and Applied Sciences, 12, 1179-1185.

23.Hany A. Elazab, S. Moussa, B. Gupton, M. El-Shall Journal of Nanoparticle Research. 2014, 16, 1-11.

24.Hany A. Elazab, S. Moussa, A. Siamaki, B. Gupton, M. El-Shall Catalysis Letters, 147, 1510-1522.

25.Hany A. Elazab, A. R. Siamaki, S. Moussa, B. F. Gupton, M. S. El-Shall Applied Catalysis A: General. 2015, 491, 58-69.

26.Hany A. Elazab, S. Moussa, K. W. Brinkley, B. Frank Gupton, M. Samy El-Shall Green Processing and Synthesis, 6, 413-424.

27.Hany A. Elazab, Mamdouh Gadall, M. A. Sadek, Tamer T. El-Idreesy, Biointerface Research in Applied Chemistry, 2019.

28.M. A. Radwan, Mohamed Adel Rashad, M. A. Sadek, Hany A. Elazab, Journal of Chemical Technology and Metallurgy, 2019.

29.Hany A. Elazab, S. A. Hassan, M. A. Radwan, M. A. Sadek, International Journal of Innovative Technology and Exploring Engineering (IJITEE), 2019.

30.Hany A. Elazab, M. M. Seleet, Said M. A. Hassanein, M. A. Radwan, M. A. Sadek, International Journal of Innovative Technology and Exploring Engineering (IJITEE), 2019

31.Hany A. Elazab, M. M. Seleet, Said M. A. Hassanein, M. A. Radwan, M. A. Sadek, International Journal of Innovative Technology and Exploring Engineering (IJITEE), 2019.

32.Hany A. Elazab, M. M. Seleet, Said M. A. Hassanein, M. A. Radwan, M. A. Sadek, International Journal of Innovative Technology and Exploring Engineering (IJITEE), 2019.

33.Hany A. Elazab, M. A. Sadek, Tamer T. El-Idreesy, Journal of Chemical Technology and Metallurgy, 2019.

34.Sherif Elbasuney, M. A. Radwan, Hany A. Elazab, Journal of Chemical Technology and Metallurgy, 2019.

35.Sherif Elbasuney, M. A. Radwan, Hany A. Elazab, Journal of Chemical Technology and Metallurgy, 2019. 